\title{
Interactive comment on "Air Quality and Climate Change, Topic 3 of the Model Inter-Comparison Study for Asia Phase III (MICS-Asia III), Part II: aerosol radiative effects and aerosol feedbacks" by Meng Gao et al.
}

\section{Anonymous Referee \#1}

Received and published: 20 September 2019

General comments: The manuscript entitled "Air Quality and Climate Change, Topic 3 of the Model Inter-Comparison Study for Asia Phase III (MICS-Asia III), Part II: aerosol radiative effects and aerosol feedbacks discussed the estimates of aerosol radiative forcing, aerosol feedbacks and the dominant roles of direct forcing. The possible causes for the differences among the models were also analyzed by sensitivity simto be improved in writing and logically organization in its structure. I recommend to publish it after major revision. 
Specific comments: 1 . There are a few grammatical errors, please find a native speaker to proofread the paper. 2. The sections of manuscript need to be organized more logically in structure. 3. Lines 61-65: Some important previous work in China from the observational perspective have been ignored, including Huang et al., Satellite-based assessment of possible dust aerosols semi-direct effect on cloud water path over East Asia, 2006; Liu et al., Aerosol optical properties and radiative effect determined from sky-radiometer over Loess Plateau of Northwest China, 2011; Also, Line 82-89: some modeling work have been ignored, including Chen et al., Modeling the transport and radiative forcing of Taklimakan dust over the Tibetan Plateau, 2013; Chen et al., Dust modeling over East Asia during the summer of 2010 using the WRF-Chem model, 2018; Liu et al., Modeling study on the transport of summer dust and anthropogenic aerosols over the Tibetan Plateau, 2015; Jia et al., Estimation of the aerosol radiative effect over the Tibetan Plateau based on the latest CALIPSO product, 2018. These researches are highly relevant to the topic investigated here. 4. Line 66-69, please cite the previous researches as an illustration basis. 5. Lines 80-81, the meaning of theory and practice of studying aerosol feedbacks over Asia should be illustrated in detail. 6. Please add a section to describe the model and research methodology. Move the illustration in Line 90-101 and Line 157-159 to the new section. 7. Please give the detailed description when the abbreviation first appears (for example, M1, M2, M3...M7). 8. Please use the box or symbol to show the BTH region, Huabei province and Beijing in Figure 1. 9. Line 118-119, the description is inconsistent with Table 1. 10. Line 145-149, why do you only use M4 and M5 to provide direct and indirect aerosol radiative forcing? Why do you only use M5 to study the effects of aerosols mixing state, hygroscopic growth, black carbon and mineral dust. Obviously, the values given by these models are very different. Which should be illustrated. 11. Line 195196, the description is inconsistent with Table 3. M2 (12.9) 12. Please add a discussion about the simulation performance of different models. 13. Line 271-272iijŇplease give some evidence for that the effect of $\mathrm{BC}$ indicates smaller than that of other scattering aerosols. How about the effect of sulfate aerosol?

Interactive 
Technical corrections: 1. Line 110, 'In Sect. 2'??? Please check it. 2. Line 118, Please give the full spelling of BTH when the abbreviation appears at the first time. 3 . Line 118, 'reports' should be changed to 'report'. 4. Line 121, Please give the full spelling of AOD. 5. Line 257, 'by dust' should be changed to 'of dust'.

Interactive comment on Atmos. Chem. Phys. Discuss., https://doi.org/10.5194/acp-2019-719, 2019. 